\title{
Dietary vitamin D supplementation improves haematological status following consumption of an iron-fortified cereal: an 8-week randomised controlled trial
}

\author{
Sohail Mushtaq ${ }^{1}$ and Salma F. Ahmed Fuzi ${ }^{2}$ \\ ${ }^{1}$ University of Chester, Chester, United Kingdom and \\ ${ }^{2}$ Universiti Putra Malaysia, Selangor, Malaysia
}

\section{Abstract}

Vitamin D, a secosteroid, has recently been implicated in the stimulation of erythroid precursors and ultimately the rate of erythropoiesis. However, there are a paucity of randomised controlled trials (RCT), investigating the effect of vitamin D supplementation iron status, especially in populations at risk of iron deficiency. An eight-week, double-blind RCT was carried out in 50 female (mean age ( \pm SD): $27 \pm 9$ years), iron-deficient (plasma ferritin concentration $<20 \mu \mathrm{g} / \mathrm{L}$ ) participants, randomised to consume an ironfortified cereal containing $9 \mathrm{mg}$ of iron, with either a vitamin D supplement (1,500 international units (IU)/day, $38 \mu \mathrm{g} / \mathrm{day}$ ) or placebo. The effect of dietary vitamin D supplementation on haematological indicators was investigated. Blood samples were collected at baseline, 4-weeks and 8-week timepoints for measurement of iron and vitamin D status biomarkers. The effect of intervention was analysed with a mixed-model repeated measures ANOVA using IBM SPSS statistical software (Version 21, IBM Corporation, New York, USA). Significant increases were observed in two haematological parameters: haemoglobin concentration and haematocrit level from baseline to post-intervention in the vitamin D group, but not in the placebo group. The increase from baseline to post-intervention in haemoglobin concentration in the vitamin D group $(135 \pm 11$ to $138 \pm 10 \mathrm{~g} / \mathrm{L})$ was significantly higher than in the placebo group $(131 \pm 15$ to $128 \pm 13 \mathrm{~g} / \mathrm{L})(\mathrm{P} \leq 0.05)$. The increase in haematocrit level from baseline to post-intervention was also significantly higher in the vitamin D group $(42.0 \pm 3.0$ to $43.849 \pm 3.4 \%)$ compared to the placebo group $(41.2 \pm 4.3$ to $40.7 \pm 3.6 \%)(\mathrm{P} \leq 0.05)$. Despite non-significant changes in plasma ferritin concentration, this study demonstrates that dietary supplementation with $1,500 \mathrm{IU}$ vitamin D, consumed daily with an iron-fortified cereal led to improvement in haemoglobin concentration and haematocrit levels in women with low iron stores. Further long-term studies are required, however, these findings suggest a potential role for improvement of vitamin D status as an adjunct therapy for recovery of iron status in iron-deficient populations.

\section{Conflict of Interest}

There is no conflict of interest. 